\title{
RETROSPECTIVE STUDY OF HISTOIMORPHOLOGY OF MUCORMYCOSIS SEEN IN COVID 19 PATIENT WITH SPECIAL COIMIMENT ON ANGIOINVASION.
}

KEY WORDS: COVID 19, Mucormycosis, Angioinvasion

\section{Dr Akash K}

\section{Dr Satish} Arakeri*

\section{Dr Mamatha K}

Postgraduate student, MD Pathology, BLDE( Deemed to be University), Shri B M Patil medical college, hospital and research center,Vijayapur.

Associate Professor,Department of Pathology,BLDE( Deemed to be University), Shri B M Patil medical college, hospital and research center, Vijayapur. *Corresponding Author

Associate Professor, Department of Pathology, BLDE( Deemed to be University), Shri B M Patil medical college, hospital and research center, Vijayapur.

Assistant Professor,Department of Pathology,BLDE( Deemed to be University), Shri B M Patil medical college, hospital and research center, Vijayapur.

Dr Sai Kulkarni

Introduction: COVID 19 infection has caused a pandemic across the globe for continuous 2-3 years as it started its journey in Huan city of china in 2019, hence it got its name as COVID 19. Aims and Objectives: To assess the fungal nfections (mucormycosis, Apergillus and candida) in post covid patients. Methodology: Total 59 cases of COVID 19 infections with fungal infection were included. Results: Out of 59 cases, 46 cases showed mucormycosis, 7 showed aspergillus and 6 cases showed mixed infection (> one species of fungal organism). Discussion: Most commonly the fungal infection occurs in the paranasal sinuses. Usually such patient's presents with severe headache, blurring of vision and overlying skin discoloration. The best non invasive modality for diagnosis is the CT scan of paranasal sinus. It shows diffuse thickening of sinus mucosa with irregular surface and bone erosion particularly orbital bones. It leads to invasion into the orbital cavity as well as with cranial cavity which has $100 \%$ mortality. Conclusion: Fungal infections in COVID 19 patients are dreadful and it causes high mortality. Most common fungal infection is Mucormycosis followed by Apsergillus and Candida.

\section{INTRODUCTION:}

COVID 19 infection has caused a pandemic across the globe for continuous 2-3 years as it started its journey in Huan city of china in 2019, hence it got its name as COVID 19. It is highly contagious enveloped RNA virus mainly infecting the respiratory tract. Usually patient will present with high degree fever, cough, loss of taste, severe myalgia etc. These symptoms are partially relieved by taking medications, but not fully controlled. These COVID 19 infection in the first wave i.e 20192020 mainly affects elderly population specifically who have comorbid condition like Diabetes, Lung disease etc ${ }^{1,2}$.

The mortality rate was comparatively less. The OCVID 19 infection in the second wave i.e 2020-2021 has created a havoc with rapid rise in the number of cases. In this wave, it was mainly affecting the young population in the age group of 20-40yrs irrespective of comorbid condition. Even elderly individuals are affecting but with comorbid conditions like diabetes, any chronic disease etc. In such individual, a very dreadful fungal infection affected the rhino-sino-nasal cavity i.e mucormycosis. Usually mucormycosis occurs in a individual with decreased immune condition particularly in diabetes patients. But during the COVID19 second wave, the incidence has increased exponentially with high mortality rate. Usually such patients present with severe headache, blurring of the vision. Some patient do have overlying skin necrosis ${ }^{3,4,5}$.

In the present study, a sincere has been made to study the incidence of mucormycosis with assessment of its severity in the form of angioinvasion.

\section{AIMS AND OBJECTIVES:}

1. To assess the fungal infections (mucormycosis, Apergillus and candida ) in post covid patients

2. To assess the angioinvasion of fungal elements

\section{METHODOLOGY:}

Total 59 cases of COVID 19 infections with fungal infection were included in the present study. All the patients were COVID 19 positive by RTPCR method. Patients clinically suspected to have fungal infection, underwent debridement procedures of paranasal sinuses and the samples were sent for histopathological for confirmation. The study period was of 2 months duration (May and June 2021)

\section{RESULTS:}

All the 59 samples were processed like routine histopathology procedure. Routine staining i.e Hematoxylin and Eosin has been done. All the slides have been reviewed by two consultant pathologist. Special stains like Periodic Acid Schiff (PAS) test has been done in all the 59 cases.

Morphological criteria for different fungal infection: $:^{6,7,8}$

Mucormycosis : 7-30 $\mu \mathrm{m}$ Broad aseptate hyphae branching at irregular angles and intervals

Aspergillus: 2-4 $\mu \mathrm{m}$ thin septate hyphae with dichotomus branching at 45 degree angle.

Candida: Budding yeast cells with pseudohyphae.

Out of 59 cases, 46 cases showed mucormycosis, 7 showed aspergillus and 6 cases showed mixed infection ( $>$ one species of fungal organism).

Out of 6 cases of mixed infection, 4 cases showed co-infection of mucormycosis + aspergillus and 2 cases showed mucormycosis, aspergillus + candida.

\section{All fungal organisms are positive for PAS stain.}

Angioinvasion is also studied in the present study. Angioinvasion is defined as presence of fungal hyphae within the lumen of blood vessels fully covered by endothelium or rupture of blood vessels wall in the vicinity of fungal colonies 
with presence of fungal organism within the lumen of blood vessels.

In the present study, Angioinvasion was seen in 25 cases ( total 59 cases). Out of which, 20 were mucormycosis, 2 were aspergillosis and other 3 showed mixed infection.

\section{DISCUSSION}

COVID 19 infection is associated with wide range of fungal infections. The probable hypothesis may be due to decreased immunity as well as decreased oxygen availability at the tissue level, increased availability of glucose( in diabetics), increased iron level and decreased immune function. Even the modality of treatment also most probably leads to increase in fungal infections i.e usage of steroids. Even the contrary theory also holds true that in case of autoimmune conditions like SLE, Rheumatoid arthritis, Glomerulon ephritis, steroids are used regularly for longer duration. Such patients are not prone for fungal infections. Only in patient with COVID 19 infections, there is more risk of fungal infection. The theory of usage of contaminated tap water in oxygen supplementation system may also be the logically suitable reason for fungal infections. However, whatever the reason thought of, many COVID 19 patients have fungal infection without having any known cause as mentioned above. The fungal infection creates a very difficult task to save the patient as most of them have near $100 \%$ mortality ${ }^{9,10}$.

Most commonly the fungal infection occurs in the paranasal sinuses. Usually such patient's presents with severe headache, blurring of vision and overlying skin discoloration. The best non invasive modality for diagnosis is the CT scan of paranasal sinus. It shows diffuse thickening of sinus mucosa with irregular surface and bone erosion particularly orbital bones. It leads to invasion into the orbital cavity as well as with cranial cavity which has $100 \%$ mortality.

Most common fungal infections are Mucomycosis followed by Apergillus and Candida ${ }^{11}$

Mucormycosis is known to cause fungal infections of paranasal sinuses in diabetic patients. But its incidence is drastically increased in COVID 19 infected patient. Morphologically, it is broad based aseptate branching at irregular intervals.

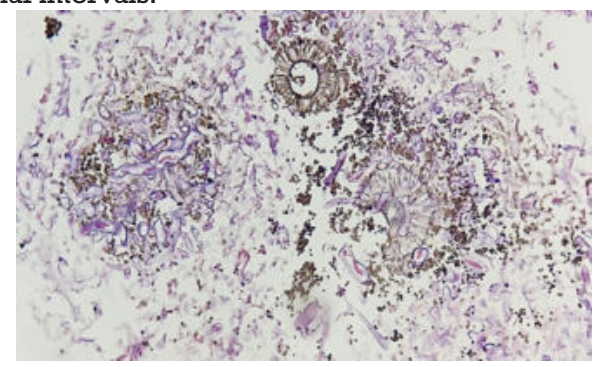

Figure No 1:Section studied shows broad based Mucormycosis and aspergillus. H\&E 40X

Aspergillus is also common in immunocompromised patients like RVD. It forms black colored colonies. Morphologically, it is thin septate branching at 45 degree.

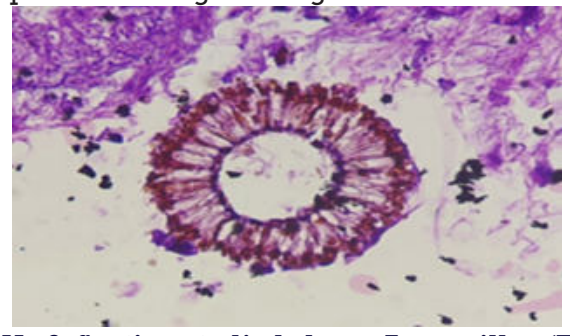

Figure No 2: Section studied shows Aspergillus (Fruiting body), PAS stain 40X

|www.worldwidejournals.com $\mid$

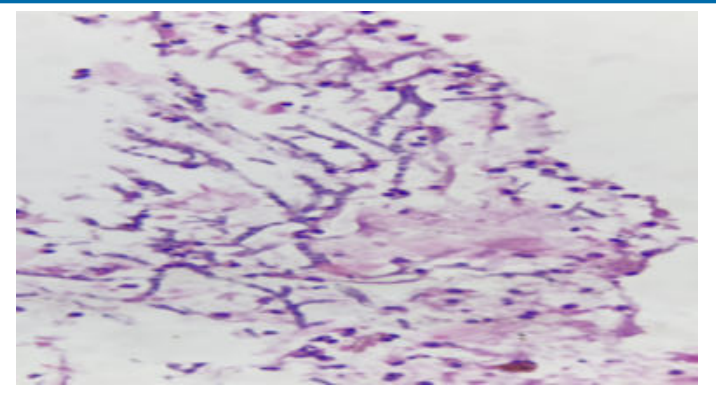

Figure No 3: Section studied shows Mycelial forms of Candida. H\&E 40X

Candida is a normal commensal of upper airway. But its presence in the sinuses is always pathological. Morphologically, it has thin elongated pseudohyphae with budding spores.

The main modality of treatment is to debride the necrotic mucosa as much as possible to decrease the burden the fungal colonies. The patients with put on antifungal drugs like Amphotericin $B^{12}$.

However, due to all available treatment modalities, the prognosis of fungal infection in COVID 19 is very bad.

\section{CONCLUSION:}

Fungal infections in COVID 19 patients are dreadful and it causes high mortality. Most common fungal infection is Mucormycosis followed by Apsergillus and Candida.

\section{REFERENCES}

1. Carfi A, Bernabei R, Landi F. Persistent Symptoms in Patients After Acute COVID-19.JAMA 2020;324(6):603-605.

2. Carvalho Schneider C, Laurent E, Lemaignen A, Beaufils E, Bourbao Tournois C, Laribi S et al. Follow-up of adults with noncritical COVID-19 two months after symptom onset. European society of clinical microbiology and infectious disease 2021;27(2):258-263.

3. Ladds E, Rushforth A, Wieringa S, Taylor S, Rayner C, Laiba $\mathrm{H}$ et al. Persistent symptoms after Covid-19: qualitative study of 114 "long Covid" patients and draft quality principles for services. British medical journal 2020;20;114.

4. Hannah D, Assaf G, McCorkel L, Wei H, Low R, Reem Y et al. Characterizing long COVID in an international cohort: 7 months of symptoms and their impact. Eclinical medicine 2021;38:1-19.

5. Ayegbusi OL, Hughes SE, Turner G, Rivera SC, McMullan C, Chandan JS et al. Symptoms, complications and management of long COVID: a review. Journal of royal society of medicine $2021 ; 114(9): 428-442$.

6. Guarner J, Brandt ME. Histopathologic Diagnosis of Fungal Infections in the 21 st Century. Clin Microbiol Rev.2011 Apr;24(2):247-280.

7. Ghosh A, Magar DG, Thapa S, Nayak N, Talwar OP. Histopathology of important fungal infections - a summary. Journal of Pathology of Nepal (2019) Vol 9, 1490-1496.

8. Sangoi AR, Rogers WM, Longacre TA, Montoya JG, Baron EJ, Banaei N Challenges and Pitfalls of Morphologic Identification of Fungal Infections in Histologic and Cytologic Specimens: A Ten-Year Retrospective Review at a Single Institution. American Journal of Clinical Pathology, Volume 131, Issue 3, March 2009,Pages 364-375.

9. Singha AK, Singh R,.Joshi SR, Misra A. Mucormycosis in COVID 19: A Systematic review of cases reported worldwide and in India. Diabetes \& Metabolic Syndrome: Clinical Research \& Reviews 2021;15(4): 1-8.

10. Garg D, Muthu V, Sehgal IS, Ramachandran R, Kaur H, Bhalla A, et al. Coronavirus Disease (Covid-19) Associated Mucormycosis (CAM): Case Report and Systematic Review of Literature. Mycopathologia 2021: 1-10

11. Raut $A$, Huy NT. Rising incidence of mucormycosis in patients with COVID-19: another challenge for India amidst the second wave?. The LANCET Respiratory medicine 2021;9(8):E77

12. AL Tawfiq JA, Alhumaid S, Alshukairi AN, Temsah MH, Barry M, Mutair AA et al. COVID-19 and mucormycosis superinfection: the perfect storm. Infection 2021;49:833-853. 